\title{
The limited validity of the criteria of the American College of Rheumatology for classifying gout patients in primary care
}

Hein JEM Janssens, ${ }^{1}$ Mathijs Janssen, ${ }^{3}$ Eloy H van de Lisdonk, ${ }^{1}$ Jaap Fransen, ${ }^{2}$ Piet LCM van Riel, ${ }^{2}$ Chris van Weel. ${ }^{1}$

${ }^{1}$ Department of Primary and Community Care, Radboud University Nijmegen Medical Centre, Nijmegen, Netherlands (HJEM Janssens MD, EH van de Lisdonk PhD, Prof C van Weel PhD).

${ }^{2}$ Department of Rheumatology, Radboud University Nijmegen Medical Centre, Nijmegen, Netherlands (J Fransen PhD, Prof PLCM van Riel PhD).

${ }^{3}$ Department of Rheumatology, Rijnstate Hospital, Arnhem, Netherlands (M Janssen PhD).

Correspondence to: Hein Janssens, Department of Primary and Community Care, Radboud University Nijmegen Medical Centre, PO Box 9101, 6500 HB Nijmegen, Netherlands h.janssens@elg.umcn.nl

Key words: gout, primary care, diagnosis, sensitivity and specificity, predictive value of tests 
In order to classify gout without identification of monosodium urate (MSU) crystals, the American College of Rheumatism (ACR) formulated criteria in 1977. ${ }^{1}$ Of 11 criteria, 6 or more have to be present to classify patients as having gout. The criteria were not developed with reference to MSU crystals, nor were they tested properly afterwards against this gold standard. ${ }^{1,2,3}$ But, as they are widely used, and cited, testing their validity is critical to our ability to understand and treat gout. ${ }^{4}$

Many gout studies include patients with 'self-reported gout', if patients fulfill the ACR criteria. Most self-reported diagnoses of gout will originate from a diagnosis made by family physicians (FPs), as most patients presenting acute gout are managed by them. ${ }^{2,5}$ That makes the primary care setting particularly relevant to test the ACR criteria.

We designed a prospective study in a Dutch primary care population $(\sim 200,000$ people) to estimate the validity of the ACR criteria (patient recruitment 2004-2006). We used identified MSU crystals as reference test, as recommended by the European League Against Rheumatism. ${ }^{2}$ Recruited patients, presenting a mono-arthritis, were included if FPs suspected gout in them. Within 24 hours an experienced rheumatologist assessed the ACR criteria, and analyzed aspirated synovial fluid for MSU crystals in all patients - with and without a FPs' diagnosis of gout. If MSU crystals could not be identified, patients were assessed for other joint diseases. If MSU crystals were identified during follow-up, the patient was re-classified as having 'gout', with an initial false-negative test. To calculate test characteristics, $2 \times 2$ tables were used.

Table 1. The $2 \times 2$ table with ' 6 or more positive ACR-criteria' as index test and MSUcrystals, identified in the synovial fluid of the affected joint, as reference test, in 328 patients with a gout diagnosis according to the FP.

\begin{tabular}{l|c|c|c} 
& $\begin{array}{c}\text { MSU-crystals } \\
\text { identified }\end{array}$ & $\begin{array}{c}\text { No MSU-crystals } \\
\text { identified }\end{array}$ & \\
\hline 6 or more positive & 168 & 43 & 211 \\
ACR-criteria & 41 & 76 & 117 \\
\hline $\begin{array}{l}\text { Less than 6 positive } \\
\text { ACR-criteria }\end{array}$ & 209 & 119 & 328 \\
\hline
\end{tabular}

Of 381 patients presenting a mono-arthritis, 159 (42\%) had their MTP1 joint affected, 222 $(58 \%)$ an other joint. In 328 (86\%) patients FPs made a gout diagnosis; mean age $58.0 \mathrm{yr}$ (SD:13.5); male $261(80 \%)$; MSU crystals identified in $209(64 \%)$ - in 202 at the initial investigation and in 7 during follow-up. In 53 patients FPs suspected no gout - MSU crystals in $7(13 \%)$.

The ACR criteria showed a limited validity: sensitivity 0.80 , specificity 0.64 , positive predictive value 0.80 , and negative predictive value 0.65 (table 1 ). After modifying the cut-off point of 6 or more positive items test characteristics did not substantially improve (table 2). 
Table 2. The test characteristics of different numbers of positive ACR-criteria (index tests) using the identification of MSU-crystals as reference test in 328 patients with a gout diagnosis according to the FP.

\begin{tabular}{lccccc}
\hline $\begin{array}{l}\text { Number of } \\
\text { positive } \\
\text { criteria }\end{array}$ & Sensitivity & Specificity & $\begin{array}{c}\text { Positive } \\
\text { predictive } \\
\text { value }\end{array}$ & $\begin{array}{c}\text { Negative } \\
\text { predictive } \\
\text { value }\end{array}$ & $\begin{array}{c}\text { Overall } \\
\text { fraction } \\
\text { correct }\end{array}$ \\
\hline 4 or more & 1.00 & 0.24 & 0.70 & 0.97 & 0.72 \\
& $(208 / 209)$ & $(28 / 119)$ & $(28 / 119)$ & $(28 / 29)$ & $(236 / 328)$ \\
5 or more & 0.95 & 0.35 & 0.72 & 0.79 & 0.73 \\
& $(198 / 209)$ & $(41 / 119)$ & $(198 / 276)$ & $(41 / 52)$ & $(239 / 328)$ \\
6 or more & $\mathbf{0 . 8 0}$ & $\mathbf{0 . 6 4}$ & $\mathbf{0 . 8 0}$ & $\mathbf{0 . 6 5}$ & $\mathbf{0 . 7 4}$ \\
& $(\mathbf{1 6 8 / 2 0 9 )}$ & $\mathbf{( 7 6 / 1 1 9 )}$ & $\mathbf{( 1 6 8 / 2 1 1 )}$ & $\mathbf{( 7 6 / 1 1 7 )}$ & $\mathbf{( 2 4 4 / 3 2 8 )}$ \\
7 or more & 0.57 & 0.82 & 0.85 & 0.52 & 0.67 \\
& $(120 / 209)$ & $(98 / 119)$ & $(120 / 141)$ & $(98 / 187)$ & $(218 / 328)$ \\
8 or more & 0.26 & 0.93 & 0.87 & 0.42 & 0.51 \\
& $(55 / 209)$ & $(111 / 119)$ & $(55 / 63)$ & $(111 / 265)$ & $(166 / 328)$ \\
9 or more & 0.07 & 0.99 & 0.94 & 0.38 & 0.41 \\
& $(15 / 209)$ & $(118 / 119)$ & $(15 / 16)$ & $(118 / 312)$ & $(133 / 328)$ \\
\hline
\end{tabular}

Malik et al. tested recently the ACR-criteria, as we did, against the gold standard, reporting comparable, moderate test characteristics (sensitivity 0.70 , specificity 0.78). However, important differences exist between our both studies. We studied patients presenting gouty joint symptoms to FPs, while Malik studied patients selected in a rheumatology clinic "only because they had had synovial fluid aspirated and analyzed at some time". In our study most patients presented a MTP1 arthritis and occasionally a knee arthritis (as can be expected in primary care), but in Maliks' study more than $75 \%$ of the patients had an aspiration from the knee and only a few from MTP joints.

Our findings pertain to patients with mono-articular gout according to FPs. This reflects the primary care setting, where most cases of gout are mono-articular and occasionally oligo- or polyarticular. ${ }^{5}$

Aspirated fluid was sensitively searched for crystals, and detected crystals were specifically identified by rheumatologists with experience in synovial fluid analysis. The proportion of patients at risk for a false negative test was low in our study.

We tested the ACR criteria in a relevant population representative for patients having gout diagnosed by doctors without joint fluid investigation. Additionally to Maliks' study, ${ }^{3}$ our findings show the limited validity of the ACR criteria, and support the empirical evidence ${ }^{4}$ of interpreting with caution the estimates of incidence and prevalence, ${ }^{6}$ causal associations, ${ }^{7.8}$ and effects of interventions, ${ }^{9}$ in studies which used the ACR criteria for patient inclusion. 


\section{Conflict of interest statement}

We declare that we have no conflict of interest.

\section{Acknowledgments}

We are thankful to the 93 family doctors working in Arnhem/Liemers and surroundings who selected the patients; the patients who were willing to participate the study; Tonnie Berends, Carla De Gendt, Alphons de Jong, Henk Visser (Department Rheumatology, Rijnstate Hospital Arnhem), Twanny Jeijsman-Rouwhorst, Jan van Doremalen (Department of Primary and Community Care, Radboud University Nijmegen) for facilitating the data collection.

\section{References}

1. Wallace SL, Robbinson H, Masi AT, Decker JL, McArty DJ, Yü T. Preliminary criteria for the classification of the acute arthritis of primary gout. Artritis Rheum 1977;20:895-900.

2. Zhang W, Doherty M, Bardin T, Pascual E, Barskova V, Conaghan P, et al. EULAR evidence based recommendations for gout. Part I: Diagnosis. Report of a task force of the Standing Committee for International Clinical Studies Including Therapeutics (ESCISIT). Ann Rheum Dis 2006;65:1301-11.

3. Malik A, Schumacher HR, Dinnella JE, Clayburne GM. Clinical diagnostic criteria for gout: comparison with the gold standard of synovial fluid crystal analysis. J Clin Rheumatol 2009;15:22-4.

4. Johnson SR, Goek ON, Singh-Grewal D, Vlad SC, Feldman BM, Felson DT, Hawker GA, Singh JA, Solomon DH. Classification criteria in rheumatic diseases: a review of methodologic properties. Arthritis Rheum 2007;57:1119-33

5. Owens D, Whelan B, McCarthy G. A survey of the management of gout in primary care. Ir Med J 2008;101:147-9.

6. Arromdee E, Michet CJ, Crowson CS, O'Fallon WM, Gabriel SE. Epidemiology of gout: is the incidence rising? J Rheumatol 2002;29:2403-6.

7. Choi HK, Atkinson K, Karlson EW, Willett W, Curhan G. Alcohol intake and risk of incident gout in men: a prospective study. Lancet 2004;363:1277-81.

8. Choi HK, Atkinson K, Karlson EW, Willett W, Curhan G. Purine-rich foods, dairy and protein intake, and the risk of gout in men. N Engl J Med 2004;350:1093-103.

9. Schumacher HR Jr, Becker MA, Wortmann RL, Macdonald PA, Hunt B SJ, Lademacher C, et al. Effects of febuxostat versus allopurinol and placebo in reducing serum urate in subjects with hyperuricemia and gout: A 28-week, phase III, randomized, doubleblind, parallel-group trial. Arthritis Rheum 2008;59:1540-8.

"The Corresponding author has the right to grant on behalf of all authors and does grant on behalf of all authors, an exclusive licence (or non exclusive for government employees) on a worldwide basis to the BMJ Publishing Group Ltd and its Licensees to permit this article to be published in ARD editions and any other BMJPGL products to exploit all subsidiary rights, as set out in our licence (http://ARD.bmjjournals.com/ifora/licence.pdf)." 